\title{
A cultura como estratégia política na revista Movimento, da União Nacional dos Estudantes (2001-2010)
}

Aldimara Catarina Brito Delabona Boutin ${ }^{1}$

\section{Resumo}

A partir do referencial teórico do Materialismo Histórico e Dialético, o artigo tem como objetivo evidenciar o posicionamento da revista Movimento, da União Nacional dos Estudantes (UNE), em relação à cultura. Ao realizarmos um levantamento na página digital da UNE, localizamos um total de 19 edições do periódico, publicadas entre os anos de 2001 a 2010. Após a leitura da seção de cultura, estabelecemos categorias, buscando identificar as temáticas relacionadas à cultura. $\mathrm{O}$ artigo encontra-se dividido em três partes: na primeira, apresentamos breves reflexões sobre a perspectiva teóricofilosófica de cultura no pensamento de Antonio Gramsci; sequencialmente, investigamos as iniciativas desenvolvidas historicamente pela UNE no âmbito da cultura; posteriormente realizamos análises do material empírico, buscando desvelar o posicionamento adotado pela Movimento em relação à cultura. Nas considerações finais, indicamos que a revista se posiciona em favor da cultura, enquanto instrumento para a compreensão e transformação da realidade.

\section{Palavras-chave}

Cultura. Revista Movimento. União Nacional dos Estudantes. Militância política.

\footnotetext{
${ }^{1}$ Doutora em Educação pela Universidade Estadual de Ponta Grossa, Paraná, Brasil; membro do Grupo de Pesquisa Capital, Trabalho, Estado e Educação: Políticas Educacionais e Formação de Professores. E-mail: audiboutin@hotmail.com.
} 

Union (2001-2010)

Aldimara Catarina Brito Delabona Boutin²

\begin{abstract}
Based on the theoretical references of Historical and Dialectical Materialism, the article aims to highlight the positioning of the National Students Union (UNE) movement in relation to culture. When we carried out a survey on the UNE digital page, we found a total of 19 editions of magazine, published between 2001 and 2010. After reading the culture section, we established categories, seeking to identify themes related to culture. The article is divided into three parts: the first of which presents brief reflections on the theoretical philosophical perspective of culture in the thought of Antonio Gramsci; sequentially, we investigated the initiatives developed historically by UNE in the field of culture and subsequently analyzed the empirical material, in order to highlight the position adopted by Movimento magazine in relation to culture. In the final remarks, we indicate that magazine positions itself in favor of culture as an instrument for understanding and transforming reality.
\end{abstract}

\title{
Keywords
}

Culture. Movimento Magazine. National Student Union. Political militancy.

\footnotetext{
${ }^{2} \mathrm{PhD}$ in Education, State University of Ponta Grossa, State of Paraná, Brazil; member of the Capital, Labour, State and Education Research Group: Educational Policies and Teacher Training. E-mail: audiboutin@hotmail.com.
} 


\section{Introdução}

A sociedade civil aparece em Gramsci (2016, p. 121) como uma "trama privada do Estado", na qual os "organismos privados" (GRAMSCI, 2016, p. 129) de hegemonia, representados por instituições educativas, religiosas, meios de comunicação etc., cujas perspectivas políticas e ideológicas instrumentalizam a passividade e a aceitação das desigualdades sociais como fatos naturais, contribuem para a produção do consenso em toda a sociedade.

No entanto, na sociedade civil, a produção do consenso não ocorre de maneira desvinculada da luta de classes, pois é na organização coletiva das classes subalternizadas em movimentos sociais, organizações sindicais ou partidos políticos que a luta por uma alternativa societária para além do modo de produção capitalista ganha significado.

Para Gramsci (2004), as instituições da sociedade civil, vinculadas aos interesses dos trabalhadores, podem contribuir para a formação cultural e para a apropriação de conhecimentos e experiências, de modo que homens e mulheres passem a se reconhecer como agentes de transformação social. Portanto, a elevação cultural assume papel importante na luta de classes, na medida em que auxilia no processo de compreensão ampliada da realidade, social, política e econômica, iluminando a luta pela emancipação humana.

Historicamente, a sociedade civil representada por movimentos sociais, pela mídia não hegemônica, partidos políticos, entre outras instituições, que lutam pela ampliação de direitos sociais, vem denunciando as arbitrariedades políticas de governantes e promovendo debates e eventos culturais que contribuem para expandir a visão de mundo dos segmentos explorados e, com isso, auxiliando para a tomada de consciência das situações de submissão e exploração presentes no modo de produção capitalista.

Sob a orientação do referencial teórico do Materialismo Histórico e Dialético, nosso objetivo neste artigo é evidenciar o posicionamento da revista Movimento, da União Nacional dos Estudantes (UNE), nas edições de 2001 a 2010, em relação à cultura. O recorte temporal adotado justifica-se em razão de que as edições disponíveis no acervo digital da UNE são referentes ao período supracitado.

Ao realizarmos o levantamento empírico na página digital da UNE, localizamos um total de 19 edições da revista. Após a leitura das seções de cultura de cada uma, evidenciamos a presença de matérias sobre as iniciativas realizadas pela UNE no âmbito cultural, de colunas com entrevistas ou homenagens a pessoas ligadas à cultura, sugestões de livros, filmes, músicas, documentários e debates sobre questões relacionadas à democratização da cultura e 
de políticas públicas para a cultura. Com base nesse achado, estabelecemos categorias temáticas buscando desvelar a perspectiva que orienta o posicionamento da revista Movimento sobre a cultura.

Estruturalmente, o artigo encontra-se dividido em três partes. Inicialmente, apresentamos breves considerações a respeito da perspectiva teórico-filosófica de Antonio Gramsci sobre cultura. Posteriormente, abordamos sobre algumas ações realizadas pela UNE no âmbito da cultura em diferentes períodos históricos e, na sequência, realizamos as análises do material empírico. Nas considerações finais, indicamos que os debates mais frequentes na seção de cultura da revista Movimento se organizam em torno de conteúdos que contribuem para a compreensão da realidade social, política e econômica, auxiliando para a elevação do pensamento e para a organização política dos grupos sociais subalternizados.

\section{Notas sobre a cultura na perspectiva filosófica de Antonio Gramsci}

A cultura é uma temática que está presente ao longo da obra gramsciana, sendo articulada com a formação política, a qual é essencial para a incursão dos trabalhadores na luta pela emancipação humana. Para Gramsci (2004, p. 212), "a cultura, a ampla organização do saber e da experiência significam a independência das massas em face dos intelectuais" da classe dominante, com seus projetos de poder, baseados na dominação e na acumulação privada de capital.

A noção de cultura compôs a trajetória filosófica de Gramsci, sobretudo, durante sua atividade jornalística no Partido Socialista Italiano (PSI) em 1914. Nesse momento histórico, os textos publicados pelo autor nos jornais Grido del Popolo e Avanti aparecem correlacionados com a elevação cultural, enquanto estratégia política para a formação do futuro Estado proletário.

O objetivo do autor era socializar a cultura junto aos proletários, formando intelectuais orgânicos que auxiliassem na composição de quadros militantes alinhadas ao projeto socialista. Com base nisso, em 1917, Gramsci fundou o Clube da Vida Moral, entidade político formativa de caráter cultural, organizada em torno do objetivo de "desenvolver a personalidade moral dos integrantes do clube, contribuindo para que superassem o individualismo e adquirissem uma consciência do valor da solidariedade humana" (COUTINHO, 2007, p. 20).

No entanto, foi em 1919 que a questão cultural apareceu com maior frequência no pensamento do autor, por meio de textos publicados na revista de cultura socialista $L$ ' Ordine 
Nuovo, fundada por Gramsci e pelos colegas de partido Ângelo Tasca, Palmiro Togliatti e Fernando Terracini (NOSELLA, 1992). Nas palavras de Nosella (1992, p. 31-32), a revista $L$ ' Ordine Nuovo tinha como objetivo "integrar teórica e praticamente o mundo do trabalho com o mundo da cultura" e "a ciência produtiva com a ciência humanista".

Gramsci (2004) expõe sobre a necessidade de desmistificar a cultura como algo acadêmico, livresco ou enciclopédico, no qual

o homem é visto apenas sob a forma de um recipiente a encher e entupir de dados empíricos, de fatos brutos e desconexos, que ele depois deverá classificar em seu cérebro como nas colunas de um dicionário, para poder, em seguida, em cada ocasião concreta, responder aos vários estímulos do mundo exterior. Essa forma de cultura é realmente prejudicial, sobretudo para o proletariado. Serve apenas para criar marginais, pessoas que acreditam ser superiores ao resto da humanidade porque acumularam na própria memória um certo número de dados e de datas que vomitam em cada ocasião, criando, assim, quase que uma barreira entre elas e as demais pessoas. (GRAMSCI, 2004, p. 57).

De acordo com a perspectiva teórico-filosófica de Gramsci (2004), a cultura pode ser adquirida em práticas formais de ensino, na escola, mas também nas relações de trabalho, na militância política e em instituições políticas e organizativas, como os sindicatos, os conselhos de fábrica ou os partidos políticos, ou seja, não é limitada e nem restrita ao saber enciclopédico ou formal. O autor aponta que a cultura se relaciona à "conquista da consciência superior e é graças a isso que alguém consegue compreender seu próprio valor histórico, sua própria função na vida, seus próprios direitos e seus próprios deveres" (GRAMSCI, 2004, p. 58).

Para Schlesener (2007, p. 40), embora a realidade seja concebida como um espaço em que paira a contradição, há nela "brechas" ou "pontos de cisão da hegemonia existente". A autora destaca que "a contradição gerada no mundo da produção expressa-se na cultura, no modo como os trabalhadores vivenciam as concepções de mundo recebidas e assimiladas no seio da sociedade civil" (SCHLESENER, 2007, p. 40). Assim, "as ideias e as crenças mais conservadoras convivem com elementos renovadores que se manifestam na ação, muitas vezes em contradição com os elementos culturais, morais, religiosos da concepção de mundo dominante" (SCHLESENER, 2007, p. 40).

Gramsci (2001, p. 158) confere ênfase à "hegemonia cultural" da classe dominante, a qual legitima o poder burguês, perpetuando a submissão intelectual e moral da classe trabalhadora. Sob esse pano de fundo, o autor destaca a necessidade de romper com a cultura dominante, promover o acesso ao saber sistematizado e a elevação cultural da classe 
trabalhadora, instrumentalizando a compreensão da realidade social, política e econômica (GRAMSCI, 2004).

Gramsci (1978, p. 40) nos diz que “conhecimento é poder”, pois contribui para apreender as relações sociais de produção e para movimentar homens e mulheres em direção à realização da sociedade socialista. Assim sendo,

Pode-se dizer, portanto, que a ideia de educar a partir da realidade viva do trabalhador e não de doutrinas frias e enciclopédicas, a ideia de educar para a liberdade concreta, historicamente determinada, universal e não para o autoritarismo exterior que emana da defesa de uma liberdade individualista e parcial, constitui a alma da concepção educativa de Gramsci. (NOSELLA, 1992, p. 36).

O conhecimento oriundo da socialização do saber e de práticas culturais estabelece novos consensos, instrumentalizando uma "reforma intelectual e moral" desvinculada da hegemonia burguesa. Por esse motivo, "compreender como se constitui o real para além das aparências e da ideologia dominante, que esconde as contradições que perpassam a vida dos trabalhadores implica entender o movimento de luta de classes a fim de criar formas de resistência” (SCHLESENER, 2017, p. 247).

Para Gramsci (2004), a cultura, ao passo que amplia a visão de mundo e a capacidade criativa, também auxilia na formação do pensamento autônomo e crítico. Por isso, o autor compreende que as instituições culturais, como teatros, bibliotecas, museus, entre outras, devem ser efetivamente públicas, custeadas pelo Estado, acessíveis e abertas ao grande público e não apenas a uma casta seleta de pessoas que dispõe de condições financeiras (GRAMSCI, 2001).

Iniciativas como a promoção de círculos culturais e eventos, como shows musicais, peças teatrais, recitais de poesias e exposições de obras artísticas, tanto em instituições vinculadas à sociedade civil, como também em espaços alternativos, como em praças públicas e parques, devem ser incentivadas pelo Estado, pois constituem ações educativas e, na medida em que são coletivizadas, instigam o pensamento criativo, a reflexão da realidade social, política e econômica, podendo contribuir para que as classes subalternizadas tomem consciência da relação de submissão e exploração que vivenciam cotidianamente.

Nas reflexões que dão continuidade a esse artigo, abordamos o papel da UNE na difusão cultural e na formação política dos jovens por meio da cultura. 


\section{A incursão histórica da UNE na produção e democratização da cultura junto às classes populares}

O debate em relação à democratização da cultura aparece interligado à origem da UNE, já que, no II Congresso Nacional dos Estudantes de 1938, evento inaugural da entidade, essa questão foi amplamente discutida pelos jovens que ali se faziam presentes, sendo um dos objetivos do movimento estudantil universitário (MENDES JÚNIOR, 1982).

Ao analisarmos o "Plano de sugestões para uma reforma educacional brasileira", aprovado no II Congresso Nacional dos Estudantes, evidenciamos que a cultura era considerada pelo movimento estudantil como uma estratégia para elevar o pensamento, realizar uma leitura crítica da situação econômica e social do Brasil e também como uma forma de resistência (UNE, 1938). Essa perspectiva se aproxima da concepção gramsciana de cultura, sendo relacionada à "conquista de uma consciência superior" (GRAMSCI, 2004, p. 58), capaz de fornecer os subsídios teóricos e práticos para agir sobre a realidade imediata, visando a sua transformação.

Uma das estratégias de difusão cultural que mais se destacou na UNE foi o Centro Popular de Cultura (CPC), constituído no ano de 1962, no Rio de Janeiro, em parceria com intelectuais e artistas que ensejavam produzir e divulgar um formato de arte que instigasse a reflexão crítica da realidade brasileira e atingisse amplas massas populares, conforme é possível evidenciar na exposição de motivos e objetivos, presente no relatório do CPC:

A tomada de consciência, por parte de artistas e intelectuais, da necessidade de se organizarem para atuar mais eficaz e consequentemente na luta ideológica que se trava no seio da sociedade brasileira levou-os a criar o Centro Popular de Cultura. Partindo dessa tomada de consciência, o CPC se propõe, desde o seu nascimento, a levar arte e cultura ao povo, lançando mão das formas de comunicação de comprovada acessibilidade à grande massa, e aprofundar nos demais níveis da arte e da cultura o conhecimento e a expressão da realidade brasileira. Não é propósito do CPC popularizar a cultura vigente, mas sim, através da arte e da informação, despertar a consciência política do povo. É também preocupação da UNE a valorização das expressões populares autênticas, sem perder de vista que sua organização e manutenção é mais importante que o conteúdo alienado que com frequência nelas se encontra. (CPC, s/d, p. 441-442).

O CPC da UNE propunha romper com a cultura dominante e iluminar o pensamento e a ação coletiva revolucionária, contribuindo para a superação das relações materiais de produção. Assim, considerando que "as ideias da classe dominante são, em todas as épocas, as ideias dominantes, ou seja, a classe que é o poder material dominante na sociedade é ao 
mesmo tempo o seu poder espiritual dominante" (MARX; ENGELS, 2009, p. 67), ultrapassar as fronteiras da cultura dominante, mirando em um projeto cultural que viabilize a ampla transformação social é uma questão urgente.

Os eventos culturais realizados pelo CPC da UNE em diferentes regiões ou cidades brasileiras mobilizavam "vanguardas, criando seu núcleo, aprendendo e ensinando a tornar ação social, a tornar concretos seus conhecimentos do mundo pela prática transformadora" (CPC, s/d, p. 446). Assim sendo,

a verdadeira fonte criadora dos movimentos de cultura popular são as ações feitas com o povo a partir do seu nível de consciência e utilizando seu cabedal imenso de conhecimentos práticos. A interação de um homem do povo nos movimentos de cultura popular dá-lhe, de imediato, subjetivamente, seu verdadeiro significado objetivo de agente social. Conhecendo praticamente a sua verdade, o homem do povo, adquirindo sua liberdade concreta, descobre sua potência e sua força de ser transformador. (CPC, s/d, p. 446).

Nessa perspectiva, a arte e a cultura assumem conotação política, na medida em que movimentam as classes populares a se vislumbrarem enquanto agentes dotados da capacidade de se organizarem politicamente, tendo em vista a superação das relações de domínio e exploração vivenciadas cotidianamente. O teatro foi uma das expressões artísticas que contribuiu para que isso ganhasse materialidade, sendo o "teatro de agitação política" um instrumento de difusão cultural que abordava "temas imediatos de reivindicações populares e denúncias de ações políticas, contrárias aos interesses nacionais” (CPC, s/d, p. 448).

As iniciativas realizadas no âmbito da cultura pelo CPC da UNE não estavam desvinculadas da luta política, pois,

Recusando-se a considerar a arte como "uma ilha incomunicável e independente dos processos materiais", os artistas e intelectuais do CPC acreditavam que toda manifestação cultural deveria ser compreendida exatamente "sob a luz de suas relações com a base material". Afirmavam também que "fora da arte política não há arte popular", acrescentando que era dever do homem brasileiro "entender urgentemente o mundo em que vive" para "romper os limites da presente situação material opressora". Combatendo o hermetismo da arte alienada em nome de uma arte popular revolucionária, os fundadores do CPC declaravam finalmente: "nossa arte só irá onde o povo consiga acompanhá-la, entendê-la e servir-se dela". (KORNIS, 2020, não paginado).

A proposta cultural do CPC se difundiu entre a intelectualidade artística, vinculada à esquerda, sendo duramente criticada por segmentos artísticos da direita conservadora pela 
“filiação explícita ao marxismo e a um projeto revolucionário e, principalmente, pelo enquadramento da arte como instrumento desse projeto" (ARAÚJO, 2007, p. 111). De acordo com Muller e Rezende (2011, p. 48), a articulação entre cultura e política é um elemento que instrumentaliza compreendermos o CPC como "uma das mais importantes iniciativas" da UNE, a qual possibilitava repensar "os problemas brasileiros por meio de uma perspectiva nacional-popular".

O CPC ambicionava "não só mudar a cultura dentro das universidades, mas, para além disso, pretendia exercer papel preponderante na mudança da realidade social do país" (MULLER; REZENDE, 2011, p. 48). A produção artística do CPC era socializada junto às massas com a ajuda da UNE Volante, iniciativa na qual estudantes e artistas percorriam diferentes estados e cidades brasileiras, promovendo debates políticos, shows musicais, peças de teatro, entre outros eventos (ARAÚJO, 2007).

Araújo (2007) comenta que a UNE Volante, além de promover a divulgação do CPC, colocava em pauta debates relacionados à educação, à política e à situação econômica e social brasileira:

Carlos Estevão conta que, na primeira UNE - Volante, o CPC levou três peças. Uma peça escrita por Vianinha, sobre as empresas nacionais e os sindicatos, chamada Brasil, versão brasileira. Uma outra, escrita por Arnaldo Jabor, sobre a reforma agrária: A história do formiguinho ou Deus ajuda os bão. E uma terceira peça enfocando a reforma universitária: Auto dos $99 \%$ - que foi um grande sucesso. (ARAÚJO, 2007, p. 114).

O CPC utilizava a cultura para dar visibilidade aos problemas sociais, políticos e econômicos do Brasil, movimentando a juventude em torno de um projeto de transformação radical da sociedade. Podemos evidenciar essa perspectiva no trecho do depoimento que o poeta Ferreira Gullar concedeu para a autora Araújo (2007):

O objetivo do CPC da UNE era a revolução, era a transformação da sociedade brasileira e todos esses trabalhos, evidentemente, se encaminhavam para isso, no sentido de alfabetizar o povo, fazê-lo mais consciente e, consequentemente, conduzi-lo a uma atuação transformadora da sociedade. Isso era a essência do nosso trabalho. De modo que a discussão política era permanente, não só a discussão das questões políticas como a discussão de como viabilizar a ação política através da atividade cultural, quer dizer, do cinema, do teatro, da poesia e de outras atividades que a gente ia desenvolvendo. (GULLAR, 2007, apud ARAÚJO, 2007, p. 114). 
Por meio do exposto, podemos indicar que o objetivo do CPC e da UNE Volante era divulgar uma cultura socialmente engajada, sendo que as suas criações artísticas, além de visarem à construção de uma identidade nacional, com a valorização dos produtos culturais brasileiros, eram comprometidas com a transformação da sociedade. No entanto, esse foi um dos motivos para que a UNE fosse duramente perseguida durante a ditadura militar de $1964 \mathrm{e}$ para que as atividades do CPC e da UNE Volante enfraquecessem.

No que se refere às iniciativas desenvolvidas pela UNE no âmbito da cultura após a abertura democrática, em 1985, destacamos as Bienais de Arte e Cultura, conhecidas como Bienais da UNE e o Circuito Universitário de Cultura e Arte da UNE (CUCA).

A Bienal da UNE reúne mostras universitárias de cinema, música, teatro, entre outras manifestações artísticas e culturais, em diferentes cidades brasileiras. Sendo considerado "o maior festival estudantil da América Latina" (UNE, 2020, não paginado), uma das características desse evento é a valorização da identidade nacional, por meio das "produções culturais juvenis de todas as regiões em um grande encontro" (UNE, 2020, não paginado).

A primeira Bienal da Arte e Cultura "aconteceu 20 anos após o histórico Congresso de Reconstrução da UNE, em 1979, no mesmo Centro de Convenções da Bahia. Uma grande festa celebrou a data e reuniu cerca de 6 mil estudantes" (MOVIMENTO, 2007, p. 58) em um evento, no qual se debateu

a questão da universidade, teve mostra de ciência e tecnologia, mostra literária, curtas, teatro, dança, artes visuais, artes plásticas, instalações. A abertura do evento foi feita pelo ator Francisco Milani, que na juventude atuou no CPC e no Cinema Novo, e que estava no prédio da UNE, em 1964, quando a sede foi invadida e saqueada. (ARAÚJO, 2007, p. 286).

A partir da Bienal de Salvador, a UNE fomentou discussões para a formação do CUCA, outra iniciativa da entidade no âmbito da cultura, cujo objetivo é unificar os centros culturais existentes dentro das diferentes universidades brasileiras e fomentar a formação de outros, de modo semelhante como ocorria no CPC.

A proposta do CUCA é organizar eventos culturais e debates em torno da ciência, política ou tecnologia, integrando a universidade e a sociedade, pois o "conhecimento não foi feito para ser guardado e sim compartilhado" (MOVIMENTO, 2001, p. 28) e a arte e a cultura são formas de expressar e divulgar ideias e visões que contribuem para ampliar os horizontes, pensar o mundo, compreendendo-o e, com isso, buscar transformá-lo. 
É possível afirmar que historicamente a cultura foi uma ferramenta, por meio da qual o movimento estudantil buscava dar contribuições para a compreensão da realidade social, política e econômica. O CPC, a UNE Volante, as Bienais de Cultura e o CUCA são iniciativas que, ao problematizar as relações sociais vigentes, auxiliaram para alargar as visões de mundo e para a formação do pensamento crítico e autônomo, considerando a cultura como um instrumento de luta política, conforme a perspectiva gramsciana.

Na próxima seção deste artigo, avaliamos o posicionamento adotado pela revista Movimento, da UNE, em relação à cultura, no período de 2001 a 2010.

\section{A cultura como estratégia de formação política e resistência nas páginas da revista} Movimento

A revista Movimento foi lançada durante a década de 1960 com o objetivo de levar informações e debates ao público universitário das diferentes regiões do país. Após encerrar suas atividades, durante a ditadura militar de 1964, a revista foi relançada no ano de 2001 e atualmente está disponível em formato online na página digital da UNE. Até o ano de 2010, a revista publicou um total de 17 edições, nas quais apresenta discussões sobre política, cultura, educação, economia, universidade, entre outros temas.

A questão da cultura está presente em uma seção da revista Movimento e, após realizarmos sua leitura e análise, identificamos 4 temáticas recorrentes: 1) Iniciativas da UNE no âmbito da cultura; 2) Entrevistas ou homenagens a pessoas ligadas à cultura; 3) Sugestões de livros, filmes, músicas e documentários; e 4) Democratização da cultura e políticas públicas de cultura.

Na Figura 1, sistematizamos essas temáticas, explicitando o ano e o mês de publicação de cada edição: 
Figura 1 - Temáticas presentes na seção de cultura da revista Movimento (2001-2010)

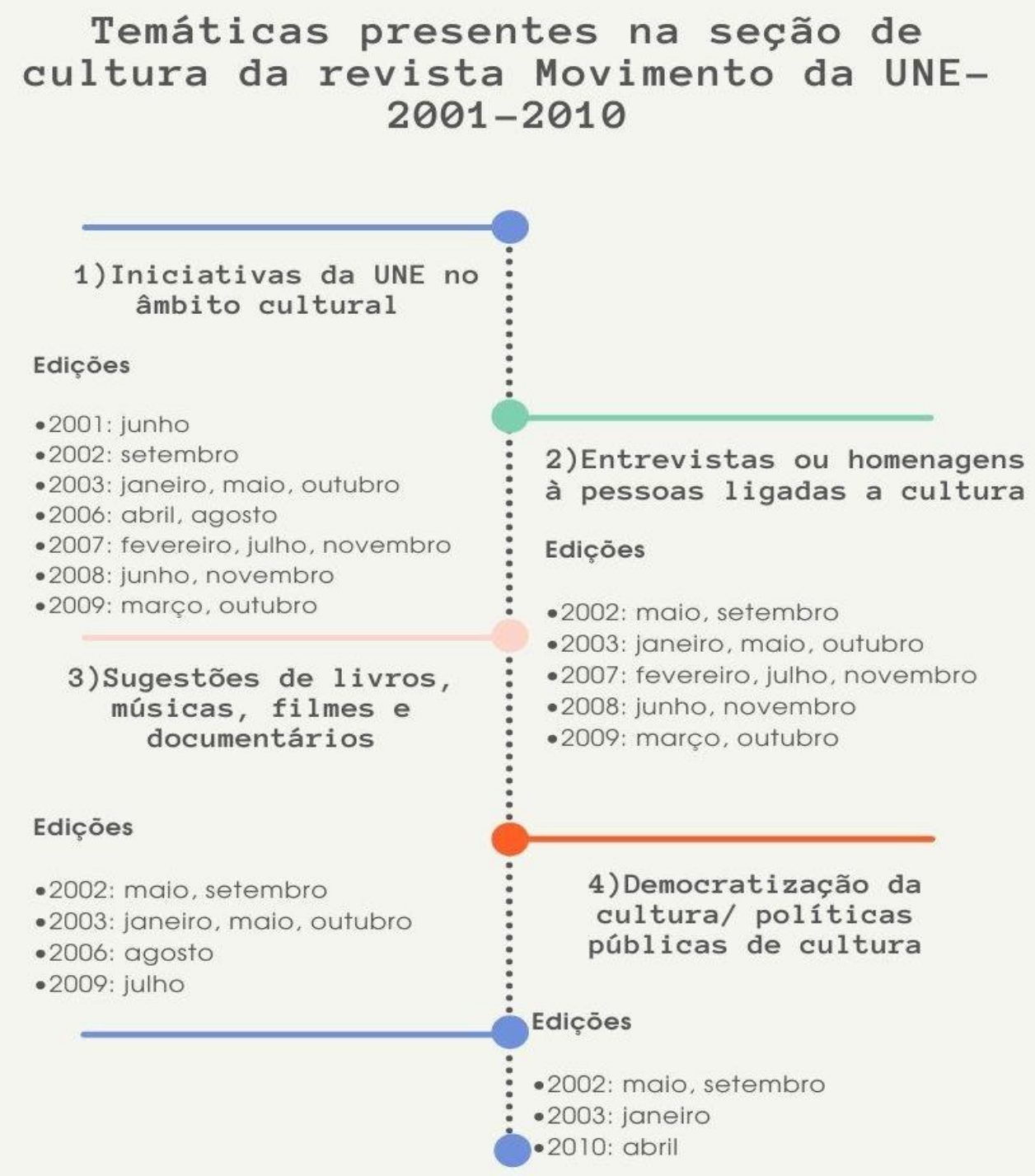

Fonte: Dados da pesquisa / Nota: Organizado pela autora

Destaca-se na seção de cultura da revista Movimento um conjunto de temáticas, dentre as quais, discussões sobre as "iniciativas da UNE no âmbito cultural" estão presentes em 14 publicações; "entrevistas ou homenagens a pessoas ligadas à arte e cultura" e "sugestões de livros músicas, filmes e documentários" estão em 12 e 7 edições, respectivamente; e o debate sobre a "democratização da cultura e políticas públicas para a cultura" se faz presente em 4 números da revista da UNE.

Verificamos que os debates presentes nessas categorias temáticas são orientados pelo objetivo de divulgar a cultura nacional, socializando tanto as obras de artistas brasileiros com representação na música, cinema, teatro e televisão, mas também a cultura alternativa 
produzida no interior das universidades, de modo a valorizar a diversidade cultural presente em nosso país e instigar a reflexão sobre a necessidade de produzir e levar a cultura a diferentes espaços e públicos.

As "iniciativas da UNE no âmbito cultural" estão presentes em um conjunto de publicações relacionadas à divulgação de eventos como as Bienais da UNE e o CUCA. Essas publicações, além de situarem o leitor quanto aos debates realizados nesses eventos, instigam reflexões sobre a necessidade de valorizar a cultura popular e a diversidade cultural brasileira, pois

Num país com tamanhas desigualdades, toda movimentação no sentido de amenizar as desigualdades é bem-vinda e a cultura não pode se furtar a esse papel. Toda atividade cultural deve se dirigir diretamente à realidade em que se encontra. [...] Defendemos que, antes de tudo, é preciso que as profundas diferenças sociais brasileiras sejam eliminadas para que a produção cultural do seu povo possa florescer em sua totalidade. (MOVIMENTO, 2003, p. $33)$.

A cultura é compreendida pelos universitários como uma alternativa para "expor e denunciar as ideologias que nos querem eternamente atrelados a interesses alheios e impedem que nossa cultura cumpra seu sentido histórico" (MOVIMENTO, 2003, p. 33). A questão da cultura, presente nessa reflexão, possui uma conotação política, visto que ao passo que é mencionada como um mecanismo controlado por grupos que manipulam os conteúdos de uma época histórica é também vista como um caminho para desvelar as relações contraditórias presentes na realidade.

Nesse sentido, o objetivo dos eventos organizados pela UNE é pensar "outra forma de fazer e viver a cultura e a arte. Interagindo com a sociedade, trocando informações e experiências, abrindo-se para novas linguagens e públicos, valorizando a (boa) produção que está à margem dos esquemas comerciais" (MOVIMENTO, 2001, p. 27).

A revista Movimento (2001), portanto, ampara-se na defesa de uma nova forma de fazer, pensar e socializar a cultura, se aproximando da concepção gramsciana de cultura, na qual o autor considera que:

Criar uma nova cultura não significa apenas realizar descobertas 'originais' individuais. Também, e mais particularmente, significa a difusão de uma visão crítica sobre verdades já descobertas, sua 'socialização' por assim dizer, e até mesmo torná-las a base da ação vital, um elemento de coordenação e ordem intelectual e moral. (GRAMSCI, 2014, p. 95-96). 
O movimento pela criação de uma nova cultura não significa desconsiderar o saber socialmente produzido e a cultura presente no cotidiano das classes populares, mas incorporálos à luta de classes, socializando os conhecimentos historicamente acumulados pela humanidade, contribuindo para ampliar as visões de mundo e as possibilidades de realizar uma "reforma intelectual e moral" (GRAMSCI, 2001, p. 182) que coloque os trabalhadores na centralidade da luta política.

As entrevistas com pessoas ligadas à arte e à cultura, publicadas pela revista Movimento (2001-2010), foram realizadas com nomes ligados ao cinema, à música e à literatura, dentre as quais destacamos o escritor Ariano Suassuna, o qual, em sua fala, abordou sobre a realidade social e política do país e a necessidade de ceder espaço e voz à cultura popular, destacando um posicionamento crítico à cultura veiculada pela imprensa hegemônica no país, conforme expressa por meio do fragmento:

As televisões querem saber é do lucro. Não querem saber se tem bom gosto, se é bom para o povo brasileiro, aquele Big Brother é uma degradação. Mas as televisões são concessionárias do Estado, acho que tinha um jeitinho da gente dar uma pressão para botar coisa boa. O que falta é vontade política. (SUASSUNA, 2003, p. 39).

A crítica em relação às grandes corporações que sufocam as produções nacionais que dão visibilidade à nossa cultura foi ampliada pela revista Movimento (2002) na entrevista concedida pela cineasta Tatá Amaral. Em sua fala, a entrevistada afirmou que no Brasil existe uma política que desvaloriza as produções nacionais e direciona a população a consumir o que é produzido por meios de comunicação, como "as televisões, as grandes gravadoras, as grandes companhias estrangeiras" (AMARAL, 2002, p. 36).

Tatá Amaral compreende que "trata-se de uma política que valoriza a passividade, que cria o espectador que deseja consumir, ao contrário do espectador que reflete e cria" (AMARAL, 2002, p. 36). Tomando isso como referência, Amaral (2002, p. 36) destacou a necessidade de utilizar a cultura como uma forma de reação à "política de exclusão social perpetrada pelos sucessivos governos brasileiros e FMI, que resultou num estado de pobreza e miséria crônica da maioria da população".

A formação pela cultura e a valorização da diversidade cultural, sobretudo da cultura produzida pelas massas, em oposição à cultura hegemônica, são elementos que circundam as reflexões da maioria das entrevistas realizadas das edições de 2001 a 2010. Se considerarmos que as ideias predominantes em determinados momentos históricos são as ideias da classe que 
detém o poder econômico, conforme sinalizam Marx e Engels (2009), uma produção cultural para além da cultura dominante é um instrumento político de luta. Desse modo,

a cultura apresenta-se aqui como um saber que se produz articulado com a ação, que pode estar voltada tanto para conservar o instituído quanto para transformá-lo. Para as classes trabalhadoras, o pensar bem produz-se na ação política, no esforço em conhecer as interações entre as condições materiais e culturais que se constroem no processo histórico, no empenho em superar preconceitos, derrubar privilégios e distinguir-se enquanto classe. (SCHLESENER, 2017, p. 245).

A estratégia de difundir e popularizar não apenas a cultura dominante, mas também as produções culturais nacionais ou de autoria dos segmentos populares excluídos ou produzidas em espaços alternativos, como universidades e comunidades de periferias, se fez presente por meio de "sugestões de livros, músicas, filmes e documentários" ao longo da seção de cultura da revista Movimento.

No conjunto das produções que dão visibilidade à cultura nacional e auxiliam para a compreensão das singularidades culturais do povo e do território brasileiro, a revista Movimento (2003, p. 36) conferiu ênfase a Graciliano Ramos, que é descrito como um escritor "fundamental" para "aprender um pouco sobre o Brasil e os brasileiros" e cuja obra contribui para a compreensão da "situação social" do sertão. A revista Movimento (2003) enfatizou o compromisso de Graciliano com os segmentos explorados, destacando a sua militância comunista e a sua prisão política durante o Estado Novo.

No que se refere às produções musicais, a revista Movimento (2003) reforça as sugestões em torno do samba de raiz, destacando nomes como Noel Rosa e Adoniran Barbosa, os repertórios que compõem a obra de ambos e as influências culturais de matriz africana das produções musicais dos subúrbios cariocas na década de 1920. A Movimento (2006) ainda traz sugestões para o cinema, as quais instrumentalizam a compreensão da realidade social e política do Brasil, como, por exemplo, o documentário $O$ sol, que retrata o período da ditadura militar de 1964 e as lutas da juventude pela democracia.

Destacamos que abordar sobre essa temática é uma questão urgente, visto que atualmente uma parcela considerável da população brasileira, apoiando-se no negacionismo da ditadura militar de 1964, defende medidas políticas extremistas e até um possível retorno de um regime militar. Debater sobre a conjuntura de 1964 auxilia para que as atrocidades vivenciadas naquele momento histórico não caiam no esquecimento ou se repitam. 
Os debates sobre a "democratização da cultura e políticas públicas para a cultura", embora tenham sido enquadrados nessa categoria, estão presentes na maioria dos artigos, entrevistas e demais conteúdos publicados pela revista Movimento (2001-2010). Esses textos apresentam, como elemento comum, a defesa da democratização da cultura, enquanto uma estratégia de "resistência" e possibilidade de superação das desigualdades sociais, pois "é no plano cultural que se encontra a possibilidade maior de superação da barbárie e da conceituação de uma outra forma democrática, justa e pluralista entre nós” (MAMBERTI, 2002, p. 27). Portanto,

é fundamental o fomento e a criação de espaços democráticos para sua discussão, com a presença efetiva de todos os atores sociais e culturais envolvidos diretamente no processo. Redefinir formas de convívio social, explodir as matrizes do pensamento excludente e embrutecedor que sedimenta o secular pacto das elites no Brasil, garantir direitos constitucionais já existentes, criar novos direitos e eliminar privilégios. São esses os compromissos essenciais para uma gestão democrática de cultura, assumindo o cidadão como prioridade. (MAMBERTI, 2002, p. 27).

O acesso coletivo a bens culturais passa pela discussão, democratização da cultura e pela sua incorporação no cotidiano das pessoas. Isso requer o desenvolvimento de políticas públicas que, ao passo que contemplem a democratização da cultura, não excluem a cultura produzida pelos segmentos populares com suas características e particularidades de cada região, pois,

Para a construção dessa política é necessária uma alteração de paradigma, para a contraposição à cultura enfeixada na elite, de pouca abrangência nacional e que mantém aquém do fazer cultural a grande maioria da população. Aí a cultura não será só mais concebida como um modelo de cultura para todos, mas com possibilidades maiores de envolvimento estratégico para a concepção da cultura por todos na construção de um projeto político de transformação social. (CESNIK; BELTRAMI, 2002, p. 33-34).

A democratização da cultura, então, não está descolada de um projeto político que, além de ampliar o acesso à bens culturais, considere a cultura popular. Para a revista Movimento (2002), isso é essencial para a criação de uma identidade que imprima uma marca às lutas e à história do povo brasileiro. Portanto, a "cultura deve ser retirada do palco, de um pedestal em que se encastelam alguns poucos heróis" (CESNIK; BELTRAMI, 2002, p. 34).

Em oposição "à implantação de programas unilaterais de cultura", a revista propõe “dar caminho à produção cultural do cidadão em todas as suas formas, em todo o país, sem 
confundi-la com práticas corporativistas", de modo a "redescobrir o sentido da ação coletiva, o sentimento de pertencimento e da participação" (MAMBERTI, 2002, p. 27). Tomando isso como referência, defende-se o desenvolvimento de políticas públicas "capazes de incrementar o acesso à criação e à informação, convertendo a cultura no veículo mais eficaz de inclusão social” (MAMBERTI, 2002, p. 27).

Ao analisarmos as temáticas que mais se destacaram na seção de cultura da revista Movimento, da UNE, pudemos evidenciar que a cultura é considerada uma estratégia de formação política que eleva o pensamento, contribui para conhecer a nossa realidade e as relações de forças que imprimem marca histórica à sociedade brasileira. Assim, a cultura impõe-se como um mecanismo que ilumina os caminhos para a luta e contribui para desvelar as ideias presentes nos projetos culturais da classe dominante, cujo objetivo é manter a classe trabalhadora em estado de passividade e submissão.

Embora a seção de cultura priorize a discussão de temáticas específicas conforme a categorização que realizamos nesse artigo, a maioria dos debates girou em torno da valorização da cultura popular, produzida em espaços e contextos diversificados ou da necessidade da democratização da cultura para as classes populares.

Ao ceder espaço e voz para que artistas, colunistas ou pessoas ligadas à arte e à cultura tecessem críticas a uma perspectiva cultural que simplifica as visões de mundo e auxilia para o conformismo, ante a realidade vivenciada no modo de produção capitalista, a revista Movimento adota um posicionamento político em favor da cultura, enquanto um instrumento de compreensão da realidade social, política e econômica, se aproximando da perspectiva cultural gramsciana.

As iniciativas desenvolvidas pela UNE no passado, por meio do CPC e da UNE Volante, almejavam despertar a consciência de classe, instrumentalizando a interpretação da "realidade efetiva" (GRAMSCI, 2016, p. 35) e auxiliando a formação de "um bloco intelectual e moral que torne politicamente possível um progresso intelectual de massa e não apenas de pequenos grupos intelectuais" (GRAMSCI, 2014, p. 103). Assim, para o movimento estudantil, a arte também é um instrumento formativo, pois o "início da elaboração crítica é a consciência daquilo que somos realmente, isto é, um conhece-te a ti mesmo como produto do processo histórico até hoje desenvolvido, que deixou em ti uma infinidade de traços recebidos" (GRAMSCI, 1978, p. 12, grifos do autor). 


\section{Considerações finais}

Nosso objetivo, neste artigo, foi evidenciar o posicionamento adotado pela revista Movimento, da UNE, no período de 2001 a 2010, em relação à cultura. Evidenciamos que os debates mais frequentes na seção de cultura da revista se fazem presentes em conteúdos que dizem respeito às iniciativas desenvolvidas pela UNE no âmbito da cultura; entrevistas ou homenagens a pessoas ligadas à arte e à cultura; sugestões de livros, músicas, filmes ou documentários; e a democratização da cultura e políticas públicas para a cultura.

No que se refere às iniciativas desenvolvidas pela UNE no âmbito da cultura, a Movimento trouxe as atrações das Bienais de Arte e Cultura e os projetos realizados pelo CUCA. Nas entrevistas realizadas com os nomes ligados à arte e à cultura, discutiu-se sobre política, economia, cultura e juventude, entre outros assuntos, com pessoas com representação no cinema, na música, teatro etc. Ainda, foram sugeridos livros, documentários, filmes ou músicas que auxiliam para a compreensão da realidade social, política e econômica e as singularidades do povo brasileiro e de sua cultura.

Por fim, ainda foram pautadas questões sobre a necessidade de promover a democratização do acesso à cultura para as classes populares, o respeito pela diversidade cultural do povo brasileiro e pela cultura produzida em diferentes espaços de convivência. Para que isso ocorra, a revista Movimento colocou como prioridade o desenvolvimento de iniciativas políticas que contemplem a cultura como uma estratégia para romper a barreira social entre dominantes e dominados.

Desse modo, para o movimento estudantil, a cultura é um instrumento de militância que converge para a compreensão da realidade social, conforme a perspectiva gramsciana. A cultura pensada, produzida e difundida, tanto no passado por meio do CPC e da UNE Volante, como também no presente com as Bienais da UNE, do CUCA e da revista Movimento, auxilia a apropriação e a difusão dos conhecimentos historicamente acumulados pela humanidade, sendo essencial para "compreender a organização material e cultural de um país em um determinado momento histórico" (SCHLESENER, 2017, p. 258).

\section{Referências}

ARAÚJO, M. P. Memórias estudantis: da fundação da UNE aos nossos dias. Rio de Janeiro: Relume Dumará, 2007.

CESNIK, F. S.; BELTRAMI, P. A. A cultura tem que ser retirada do palco. Movimento: Revista da União Nacional dos Estudantes, São Paulo, n. 5, p. 33-34, set. 2002. Disponível 
em: https://www.une.org.br/wp-content/uploads/2015/04/UNE-5\%C2\%BA-Setembro2002.pdf. Acesso em: 27 dez. 2020.

COUTINHO, C. N. Gramsci: um estudo sobre o seu pensamento político. Rio de Janeiro: Civilização Brasileira, 2007.

CPC - CENTRO POPULAR DE CULTURA. Relatório do Centro Popular de Cultura. In: BARCELLOS, J. CPC da UNE: uma história de paixão e consciência. Rio de Janeiro: Nova Fronteira, 1994. p. 441-456.

GRAMSCI, A. Cadernos do cárcere: introdução ao estudo da filosofia. A filosofia de Benedetto Croce. Rio de Janeiro: Civilização Brasileira, 2014.

GRAMSCI, A. Cadernos do cárcere: os intelectuais, o princípio educativo, jornalismo. Rio de Janeiro: Civilização Brasileira, 2001. (Coleção Cadernos do Cárcere v. 2).

GRAMSCI, A. Cadernos do cárcere: Maquiavel, notas sobre o Estado e a Política. Rio de Janeiro: Civilização Brasileira, 2016. (Coleção Cadernos do Cárcere v. 3).

GRAMSCI, A. Concepção dialética da história. Rio de Janeiro: Civilização Brasileira, 1978.

GRAMSCI, A. Escritos políticos. Rio de Janeiro: Civilização Brasileira, 2004.

KORNIS, M. A. Centro Popular de Cultura. CPDOC FGV, Rio de Janeiro, 2020. Disponível em:

https://cpdoc.fgv.br/producao/dossies/Jango/artigos/NaPresidenciaRepublica/Centro_Popular _de_Cultura. Acesso em: 27 dez. 2020.

MAMBERTI, S. Por uma cultura democrática. Movimento: Revista da União Nacional dos Estudantes, São Paulo, n. 5, p. 26-27, maio 2002. Disponível em: https://www.une.org.br/wpcontent/uploads/2015/04/UNE-4\%C2\%BA-Maio-2002.pdf. Acesso em: 27 dez. 2020.

MARX, K.; ENGELS, F. A ideologia alemã. São Paulo: Expressão Popular, 2009.

MENDES JÚNIOR, A. Movimento estudantil no Brasil. São Paulo: Brasiliense, 1982.

MOULIN, G. Um olhar feminino. Movimento: Revista da União Nacional dos Estudantes, São Paulo, n. 5, p. 35-36, set. 2002. Disponível em: https://www.une.org.br/wpcontent/uploads/2015/04/UNE-5\%C2\%BA-Setembro-2002.pdf. Acesso em: 26 dez. 2020.

MOVIMENTO: REVISTA DA UNIÃO NACIONAL DOS ESTUDANTES, São Paulo, n. 7, p. 1-45, maio 2003. Disponível em: https://www.une.org.br/wpcontent/uploads/2015/04/UNE-7\%C2\%BA-Maio-2003.pdf. Acesso em: 26 dez. 2020.

MOVIMENTO: REVISTA DA UNIÃO NACIONAL DOS ESTUDANTES, São Paulo, n. 1, p. 1-44, jun. 2001. Disponível em: https://www.une.org.br/wp-content/uploads/2015/04/UNEJunho-2001.pdf. Acesso em: 26 dez. 2020.

MOVIMENTO: REVISTA DA UNIÃO NACIONAL DOS ESTUDANTES, São Paulo, n. 4, p. 1-44, maio 2002. Disponível em: https://www.une.org.br/wpcontent/uploads/2015/04/UNE-4\%C2\%BA-Maio-2002.pdf. Acesso em: 26 dez. 2020. 
MOVIMENTO: REVISTA DA UNIÃO NACIONAL DOS ESTUDANTES, São Paulo, n. 5, p. 1-44, set. 2002. Disponível em: https://www.une.org.br/wp-content/uploads/2015/04/UNE5\%C2\%BA-Setembro-2002.pdf. Acesso em: 26 dez. 2020.

MOVIMENTO: REVISTA DA UNIÃO NACIONAL DOS ESTUDANTES, São Paulo, n. 15, p. 1-44, ago. 2006. Disponível em: https://www.une.org.br/wpcontent/uploads/2015/04/UNE-15\%C2\%BA-Agosto-2006.pdf. Acesso em: 27 dez. 2020.

MOVIMENTO: REVISTA DA UNIÃO NACIONAL DOS ESTUDANTES, São Paulo, n. 18, p. 1-55, nov. 2007. Disponível em: https://www.une.org.br/wpcontent/uploads/2015/04/UNE-18\%C2\%BA-Novembro-2007.pdf. Acesso em: 27 dez. 2020

MULLER, A.; REZENDE, T. Praia do Flamengo: 132. São Paulo: Letras Jurídicas, 2011.

NOSELLA, P. A escola de Gramsci. Porto Alegre: Artes Médicas, 1992.

MIELLI, R. O guerreiro contador de histórias. Movimento: Revista da União Nacional dos Estudantes, São Paulo, n. 7, p. 38-39, maio 2003. Disponível em: https://www.une.org.br/wpcontent/uploads/2015/04/UNE-7\%C2\%BA-Maio-2003.pdf. Acesso em: 26 dez. 2020.

SCHLESENER, A. H. Hegemonia e cultura em Gramsci. Curitiba: Editora UFPR, 2007.

SCHLESENER, A. H. Política e cultura em Gramsci. In: DEL RIO, M. (org.). Gramsci: periferia e subalternidade. São Paulo: EDUSP, 2017. p. 243-262.

UNE - UNIÃO NACIONAL DOS ESTUDANTES. Dicionário do ME: Bienal da UNE. São Paulo, 2020. Disponível em: https://www.une.org.br/dicionario-do-me/. Acesso em: 27 dez. 2020.

UNE - UNIÃO NACIONAL DOS ESTUDANTES. Plano de sugestões para uma reforma educacional brasileira, aprovado pelo segundo congresso nacional dos estudantes. In:

POERNER, A. J. O poder jovem: história da participação política dos estudantes brasileiros. Rio de Janeiro: Civilização Brasileira, 1979. p. 324-329.

Submetido em 14 de fevereiro de 2021.

Aprovado em 10 de junho de 2021. 